\title{
Analysis of the shape effect on the axial performance of a waveform micropile by centrifuge model tests
}

\author{
Young-Eun Jang' (1) $\cdot$ Jin-Tae $\mathrm{Han}^{2}$
}

Received: 24 June 2017 / Accepted: 17 April 2018/Published online: 4 May 2018

(C) The Author(s) 2018

\begin{abstract}
A new type of micropile, the waveform micropile, has been developed to provide improved load-bearing capacity compared with that of a conventional micropile. The waveform micropile has a wave-shaped grout with a partially enlarged shear key formed by the jet grouting method on the cylindrical shaft of the micropile. Previous research has determined that the waveform micropile can be installed faster than the conventional micropile and that the bearing capacity increases as the wave-shaped grout provides additional shaft resistance between the ground and the grout. In this study, a series of centrifuge model tests were conducted on the waveform micropile model with various wave-shaped grouts to analyze the relationship between the arrangement of the shear key and the load-bearing mechanism of the waveform micropile. The load-settlement relationship and the load-transfer mechanism were analyzed based on the test results of six test micropiles, including three waveform micropiles with a single shear key at various depths, one waveform micropile with a multiple shear key along the pile depth, and two micropiles with only a cylindrical shape. The test results showed that the ultimate bearing capacity of the waveform micropile was over two times greater than that of the conventional micropile. The rate of increase in the bearing capacities of each waveform micropile differed with the shape of the shear key. Furthermore, the characteristics of the load-sharing ratio due to the shaft resistance and end bearing varied depending on the shape of the waveform micropiles.
\end{abstract}

Keywords Centrifuge test $\cdot$ Jet grouting method $\cdot$ Load-sharing ratio $\cdot$ Shaft resistance $\cdot$ Waveform micropile

\section{Introduction}

A micropile is a drilled and grouted foundation system that provides relatively high bearing capacity with a small diameter ranging from 100 to $300 \mathrm{~mm}$. The micropile can be installed using fewer pieces of construction equipment than other existing foundation types. For this reason, since its introduction in Italy in the 1950s, the micropile has been recognized as an effective foundation solution for areas of limited access and low headroom. The construction process

Jin-Tae Han

jimmyhan@kict.re.kr

1 School of Geospace Engineering, Korea University of Science and Technology, 283 Goyangdae-ro, Ilsanseo-gu, Goyang 10223, Republic of Korea

2 Korea Institute of Civil Engineering and Building Technology, 283 Goyangdae-ro, Ilsanseo-gu, Goyang 10223, Republic of Korea of the micropile involves drilling the pile shaft to the required depth, installing a temporary casing, and then placing the steel rebar and grout. The high-strength steel rebar transfers the load to the surrounding ground through the grout body to develop frictional resistance. Therefore, the micropile supports the load via the shaft resistance created between the pile shaft and the ground while the load carrying capacity resulting from tip resistance is generally neglected due to small diameter of the micropile [15]. Federal Highway Administration (FHWA) micropile design guidelines specify the bond strength $\left(\alpha_{\text {bond }}\right)$ considering the frictional resistance between the grout and the ground for micropile design [10]. The $\alpha_{\text {bond }}$ ranges are classified into four types (A-D) according to the ground conditions and grouting types.

As the pile socketing length and surrounding soil conditions affect the performance of the micropile, researchers have studied methods to improve the bearing capacity by modifying the existing micropile method. In this regard, a 
new type of micropile method named the injection bore (IBO) micropile (or hollow-bar micropile) has been proposed. The hollow-bar micropile is known as the secondgeneration micropile due to its higher construction efficiency and bearing capacity relative to conventional micropiles, and its use has been increasing. Early studies indicated that the $\alpha_{\text {bond }}$ values for type B, which correspond to the pressurized grouting characteristics of the hollow-bar micropile, can lead to underestimation of the bearing capacity of hollow-bar micropiles. Therefore, various follow-up studies have been performed to propose reasonable design parameters considering the in situ conditions of the hollow-bar micropile [1, 4, 6, 11, 24].

Some researchers have focused on a helical micropile combined with a helix pile (a steel rebar with plate-type helixes) and a grouting method [7, 22, 27]. Field tests and $3 \mathrm{D}$ numerical analysis were performed to evaluate the constructability and performance of the helical micropile. In particular, the analysis results showed that the incorporation of a helix on the steel rebar provides additional bearing capacity and that the bearing capacity varies depending on the number of helixes.

In South Korea, cast-in-place piles and PHC (Pretensioned spun High strength Concrete) piles are typically used as a foundation structure. However, the micropile industry is gaining momentum as the number of construction sites with limited working spaces in urban areas continues to increase. Furthermore, the demand for improving the economic efficiency of the micropile is increasing. This is because the current design method considers only the socketed pile length into a hard layer (e.g., weathered soil and weak rock) as a bearing stratum while ignoring the shaft resistance at the upper soil layer, which has a relatively weak strength. Accordingly, efforts have been made to increase the relative capabilities of the micropile by improving the installation method and structural design to enhance the bearing capacity of state-of-theart methods [5, 18, 20].

To surpass the bearing capacity and the construction efficiency of the conventional micropile, Jang and Han [13] developed the waveform micropile, a modified version of the conventional micropile that combines the concept of the conventional micropile with the jet grouting method. Figure 1a, b shows a conceptual drawing of the conventional micropile and waveform micropile, respectively. The casing part in the soil layer of the conventional micropile is replaced with the wave-shaped grout. This method has been suggested to provide a higher bearing capacity than the conventional micropile via the mobilized frictional resistance arising between the waveform grout and compressible soil layer. The main idea of the waveform micropile construction involves shaping a waveform grout consisting of the enlarged shear key part using a pressurized jet grouting method and installing highstrength steel rebar. In previous research studies, the constructability and the increased bearing capacity of the waveform micropile were verified through both field tests and field applications. In addition, the test results showed that the waveform micropile is an effective method for reducing construction time with simplified construction steps relative to the conventional micropile [15].

The diameter of the waveform micropile is divided into the diameter $D_{1}$ of the pile shaft and the diameter $D_{2}$ of the shear key, as shown in Fig. 1b. The diameters for the pile shaft and the shear key are 300 and $500 \mathrm{~mm}$, respectively, and each part of the grout can be formed by adjusting the jet grouting pressure and working time. As shown in Fig. 1b, the length $\mathrm{L}$ of the shear key and the spacing $\mathrm{S}$ between the shear keys determine the shape of the waveform grout. The waveform micropile can be constructed with a single or multiple shear keys depending on the arrangement method of the shear key, such as the shear key number, length and spacing. According to studies on the helix micropile, the load-bearing mechanism of the pile depends on the numbers of helices [9]. The centrifuge model test and numerical analysis results of the waveform micropile also showed results similar to those of the helix micropile, showing that the bearing capacity of the pile is closely related to the shape of the waveform micropile [14]. However, in the case of helical piles with a partially extended form, such as the waveform micropile, the ratio of the diameter of the plate and the shaft is as large as $2.0-$ 6.8 [7, 23]. Moreover, the waveform micropile has a shear key-to-pile shaft ratio of only 1.6 and an internal angle of pile shaft and shear key of only 11 degrees. Therefore, we used the shaft resistance to explain the resistance by the shear key without separating the end bearing from the factors affecting the bearing capacity of the waveform micropile, as shown in Fig. 1b (ii).

In this study, a series of centrifuge model tests were conducted with the objective of investigating the relationship between the shear key shape and the axial performance of the waveform micropile. The experiment was conducted on six models, including four waveform micropiles with a single shear key, multiple shear keys added at various locations along the pile depth, and two straight micropiles without the shear key. Based on the test results, the load-settlement relationship and the loadtransfer mechanism were analyzed to investigate the axial behavior of the waveform micropiles under various configurations. In addition, the applicability of the calculation method for the bearing capacity of the conventional micropile to the waveform micropile is discussed. 


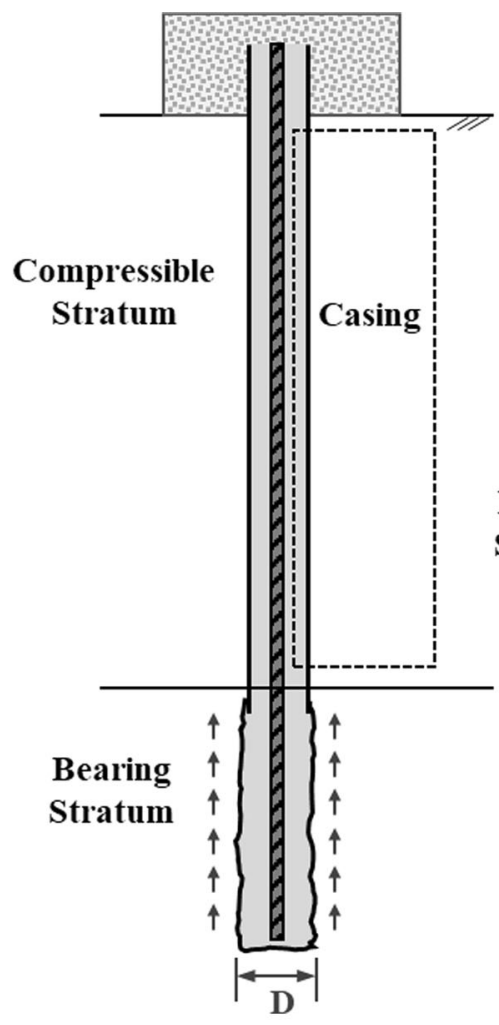

(a)

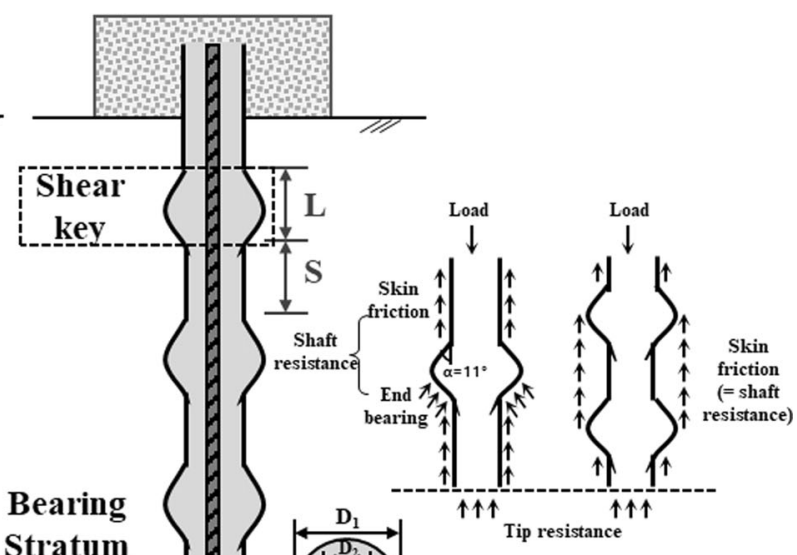

(ii) Load-bearing mechanism

(b)

Fig. 1 Conceptual drawing: a conventional micropile and $\mathbf{b}$ waveform micropile

\section{Centrifuge test}

\subsection{Facility}

The geotechnical centrifuge test is a useful experimental technique in terms of cost and time because the test enables simulation of the behavior of a small-scale model at a prototype scale to reproduce the in situ stress conditions under the required acceleration of gravity. In this study, the experiment was undertaken in a geotechnical centrifuge at the Korea Advanced Institute of Science and Technology (KAIST), South Korea, as shown in Fig. 2. The KAIST geotechnical centrifuge has a nominal radius of $5 \mathrm{~m}$ that can achieve a maximum acceleration of $130 \mathrm{~g}$ with a capacity of $1300 \mathrm{~kg}$ (2400 kg for $100 \mathrm{~g}$ ). The detailed specifications are presented in Table 1 [16]. The experiments in this study were performed under a centrifugal acceleration of $40 \mathrm{~g}$ on small-scale models manufactured according to the scale factors shown in Table 2 .

\subsection{Test models}

The test models consisted of six types of micropiles, namely the conventional micropile (labeled MP in the experiment), jet grouting micropile (JP) and four types of

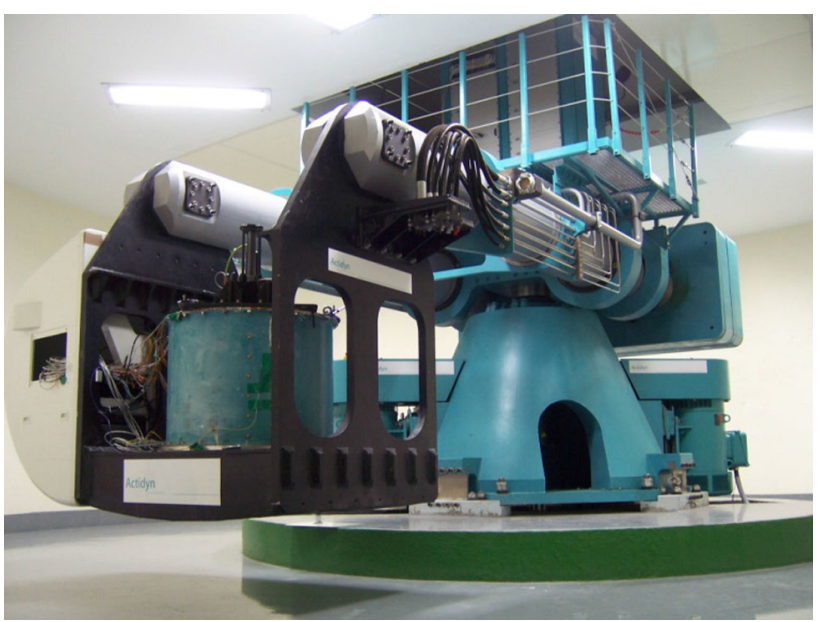

Fig. 2 KOCED geotechnical centrifuge [16]

waveform micropiles. The JP model is the same type as the waveform micropile but with only a cylindrical shaft without a shear key. Since the shaft diameters of the JP model and waveform micropiles are the same, the JP model was used to quantitatively investigate the shear key effect by comparing the behavior with the waveform micropiles. For the waveform micropile models, a single shear key was placed at the top, center and bottom of the pile for WM-A, 
Table 1 Specification of KOCED geotechnical centrifuge [16]

\begin{tabular}{ll}
\hline Description & Specification \\
\hline Manufacturer & ACTIDYN SYSTEMES SA \\
Platform radius & $5.0 \mathrm{~m}$ \\
Max. capacity & $240 \mathrm{~g}$-tons \\
Max. acceleration & $130 \mathrm{~g}$ with $1300 \mathrm{~kg}$ payload \\
Max. model payload & $2400 \mathrm{~kg}$ up to $100 \mathrm{~g}$ \\
Platform dimensions & $1.2 \mathrm{~m}(\mathrm{~L}) \times 1.2 \mathrm{~m}(\mathrm{~W}) \times 1.2 \mathrm{~m}(\mathrm{H})$ \\
Power consumption & $220 \mathrm{~kW}$ for full capacity operation \\
Fluid rotary joint & 4 lines-water and pneumatic $(700 \mathrm{kPa})$ \\
& 6 lines-hydraulic oil $(20 \mathrm{MPa})$ \\
Electrical slip rings & 8 lines for electrical power supply \\
& 30 lines for signal transmission \\
Fiber optic rotary joint & $1 \mathrm{GHz}, 2$ passages \\
\hline
\end{tabular}

Table 2 Scale factors for centrifuge modeling [19]

\begin{tabular}{llll}
\hline Quantity & Prototype/model & Quantity & Prototype/model \\
\hline Length & $\mathrm{N}$ & Mass density & 1 \\
Area & $\mathrm{N}^{2}$ & Energy density & 1 \\
Volume & $\mathrm{N}^{3}$ & Time (dynamic) & $\mathrm{N}$ \\
Velocity & 1 & Time (creep) & 1 \\
Acceleration & $1 / \mathrm{N}$ & Time & $\mathrm{N}^{2}$ \\
& & (diffusion) & \\
Mass & $\mathrm{N}^{3}$ & Frequency & $1 / \mathrm{N}$ \\
Force & $\mathrm{N}^{2}$ & Pressure & 1 \\
Energy & $\mathrm{N}^{3}$ & Flow velocity & $1 / \mathrm{N}$ \\
Stress & 1 & Flow quantity & $\mathrm{N}$ \\
Strain & 1 & Head & $\mathrm{N}$ \\
& & Capillary rise & $\mathrm{N}$
\end{tabular}

WM-B and WM-C, respectively, and multiple shear keys were applied for the WM-D. The ratio of the length (L) to the spacing (S) for WM-D was determined as 1:1, where $\mathrm{L}$ and $S$ are the same as $D_{1}(500 \mathrm{~mm})$ for the shear key diameter.

The test models were manufactured using polyvinyl chloride (PVC; Young's modulus $E=2900 \mathrm{MPa}$; Poisson ratio $v=0.4$ ) with a scale ratio of $1: 40$ as the centrifuge test was performed at a centrifugal acceleration of $40 \mathrm{~g}$ [2]. Equations 1 and 2 were used to determine the geometrical properties and dimensions of the test models.

$\frac{E_{p} A_{p}}{E_{m} A_{m}}=n^{2}$,

$L_{m}=\frac{L_{p}}{n}$, where $E_{p} A_{p}$ is the axial rigidity for the prototype pile, $E_{m} A_{m}$ is the axial rigidity for the small-scale pile, $L_{p}$ is the length for the prototype pile, $L_{m}$ is the length for the smallscale pile, and $n$ is the scaling factor.

The dimensions of the prototype and the small-scale models are presented in Table 3 and Fig. 3. All of the test models were instrumented with a pair of strain gauges (GFLA-6-50-3L) to measure the axial load distribution along the pile embedded length of $250 \mathrm{~mm}\left(L_{p}=10 \mathrm{~m}\right)$.

\subsection{Test configuration}

The soil model was prepared with dry silica sand that was artificially produced by crushing quartzite. The sand was classified as poorly graded sand (SP) according to the unified soil classification system (USCS), with a maximum and minimum unit weight of 16.1 and $12.2 \mathrm{kN} / \mathrm{m}^{3}$, respectively. The other geotechnical properties of the silica sand are shown in the particle distribution curve in Fig. 4 and Table 4.

In the centrifuge test, the soil particle size increases with increasing centrifugal acceleration. In this case, the size of the soil particle increases significantly relative to the model pile dimension, possibly leading to problematic interaction between the pile surface and the soil particle [25]. Bolton et al. [3] established that the soil particle size does not affect the result for a ratio of the diameter of the model pile $\left(D_{\mathrm{m}}\right)$ to the average soil particle size $\left(D_{50}\right)$ of 30 or more. In the present study, it was confirmed that $D_{\mathrm{m}} / D_{50}$ was 47 for MP and 78 for the other models.

The ground was prepared in a cylindrical soil container with a diameter of $0.9 \mathrm{~m}$ and a height of $0.7 \mathrm{~m}$. The airpluviation method was used to achieve the desired $70 \%$ relative density $\left(D_{\mathrm{r}}\right)$ with a soil layer of $0.4 \mathrm{~m}$. The six test models were divided into three piles, as shown in Fig. 5, and two sets of tests were conducted. The test piles were sufficiently spaced by at least nine times the minimum pile diameter to prevent interaction between the piles during the test.

Five pairs of strain gauges were attached to both sides of each model pile. As shown in Fig. 6a, the cables of the strain gauges were connected to the instrumentation system through the inside of the pile in order to prevent the cables from disturbing soil. The surface of each model pile was roughened with a silica sand coating to simulate the corresponding bonding condition for the pressurized grouting method, as shown in Fig. $6 b$ [8, 12, 26].

The piles were installed in two steps, as shown in Fig. 7. First, the sand layer was prepared until its thickness reached $250 \mathrm{~mm}$, and the pile tip was penetrated into the soil to a depth of only $100 \mathrm{~mm}$. Next, an additional soil layer was added to the first layer to a total height of 
Table 3 Configurations for centrifuge test models

\begin{tabular}{|c|c|c|c|c|c|c|c|c|}
\hline \multicolumn{3}{|c|}{ Classification } & \multicolumn{6}{|c|}{ Diameter (mm) } \\
\hline \multirow{2}{*}{$\frac{\text { No. }}{1}$} & \multicolumn{2}{|l|}{ Pile } & \multicolumn{3}{|l|}{ Prototype } & \multicolumn{3}{|l|}{ Model } \\
\hline & MP & & 180 & & & 15 & & \\
\hline 2 & JP & & 300 & & & 25 & & \\
\hline 3 & \multirow{4}{*}{$\begin{array}{l}\text { Waveform } \\
\text { micropile }\end{array}$} & WM-A & $500\left(D_{1}\right)$ & \multirow{3}{*}{$\begin{array}{l}\text { Distance from pile } \\
\text { top to shear key }\end{array}$} & 1000 & $42\left(D_{1}\right)$ & \multirow{3}{*}{$\begin{array}{l}\text { Distance from pile } \\
\text { top to shear key }\end{array}$} & 25 \\
\hline 4 & & WM-B & $300\left(D_{2}\right)$ & & 4000 & $25\left(D_{2}\right)$ & & 100 \\
\hline 5 & & WM-C & & & 8000 & & & 200 \\
\hline 6 & & WM-D & & $\mathrm{L} \& \mathrm{~S}: 1000\left(2 \mathrm{D}_{1}\right)$ & & & L \& S: 25 & \\
\hline \multicolumn{3}{|c|}{ Embedded length } & 10,000 & & & 250 & & \\
\hline
\end{tabular}

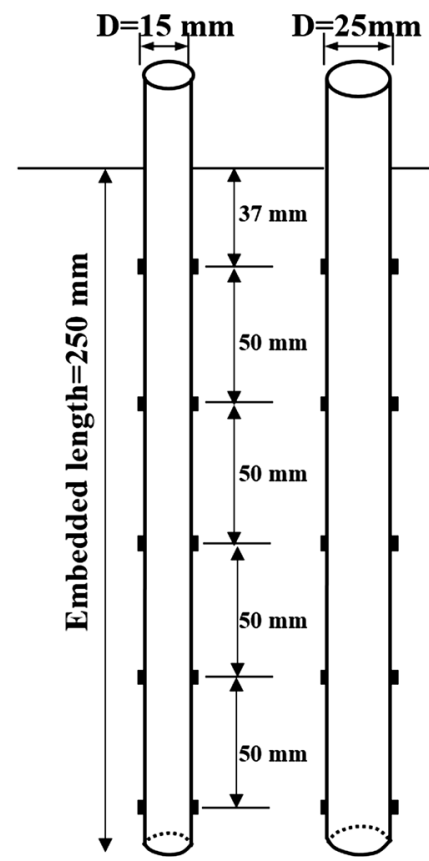

$\begin{array}{ll}\text { (a) } M P & \text { (b) } \mathrm{JP}\end{array}$

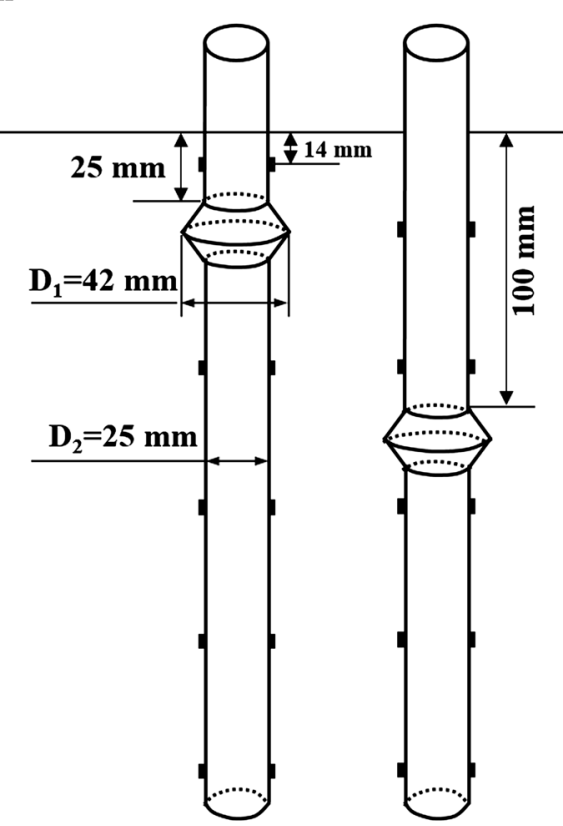

(c) WM-A (d) WM-B

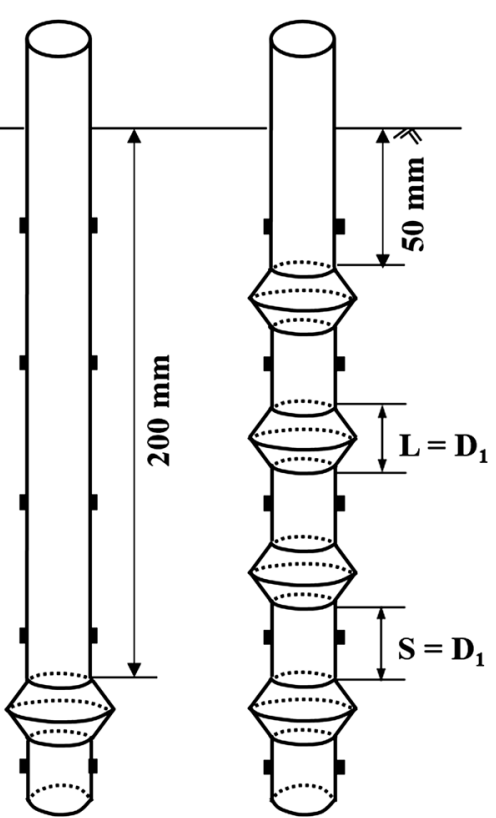

(e) WM-C (f) WM-D

-Strain gauges

Fig. 3 Test micropiles geometries

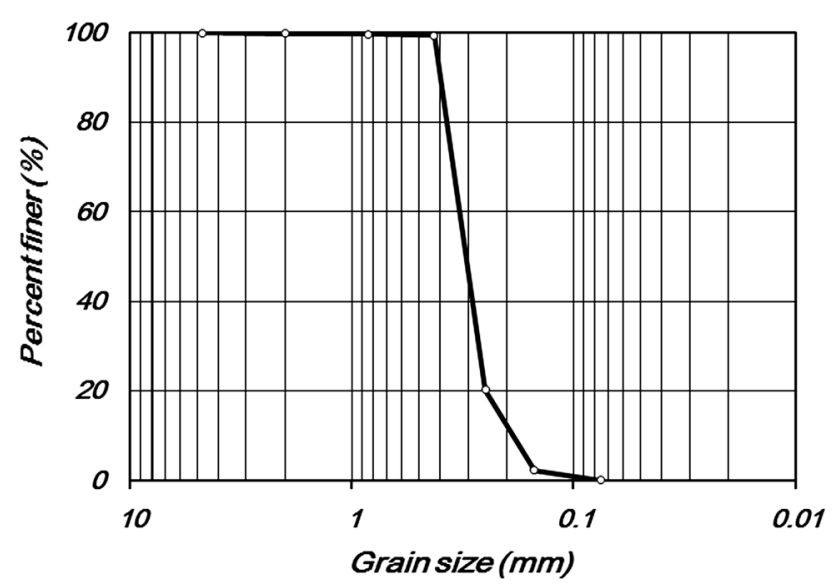

Table 4 Summary of geotechnical properties of silica sand

\begin{tabular}{ll}
\hline Description & Properties \\
\hline Specific gravity, $G_{\mathrm{s}}$ & 2.65 \\
Maximum dry density $\left(\mathrm{kN} / \mathrm{m}^{3}\right)$ & 16.1 \\
Minimum dry density $\left(\mathrm{kN} / \mathrm{m}^{3}\right)$ & 12.2 \\
Grain size $(\mathrm{mm})$ & \\
$\mathrm{d}_{10}$ & 0.19 \\
$\mathrm{~d}_{50}$ & 0.32 \\
$\mathrm{~d}_{60}$ & 0.34 \\
Soil classification, USCS & $\mathrm{SP}$ \\
Coefficient of uniformity, $C_{\mathrm{u}}$ & 1.77 \\
Plastic index, PI & $\mathrm{NP}$
\end{tabular}

Fig. 4 Particle size distribution for silica sand used in centrifuge test 


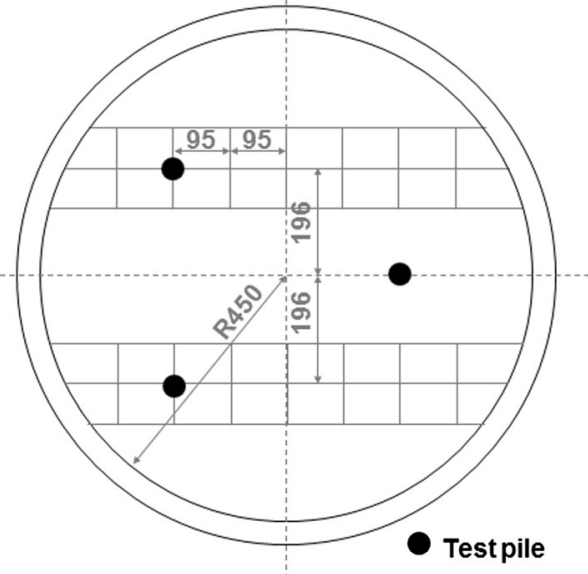

Fig. 5 Layout of centrifuge models

$400 \mathrm{~mm}$ to prevent any changes in the ground condition that might occur when the piles penetrated into the ground and to ensure that the piles were installed exactly at the desired point.

Figure 8 illustrates a schematic for the loading system in the testing program. The load cell (TCLK-5KNA) and two LVDTs were installed to measure the load-displacement relationship of the test micropiles. Strain gauges were also connected to each measurement channel. The testing was conducted using the displacement-control method with a loading rate of $0.05 \mathrm{~mm} / \mathrm{s}$ and a maximum displacement of $1.5 \mathrm{~mm}$ (60 $\mathrm{mm}$ in the prototypes).

\section{Test results and discussion}

\subsection{Ultimate bearing capacity estimation}

Figure 9 shows the axial load-settlement curves for six different micropiles in prototype units. Relative to the MP model, the JP and WM models presented stiffer behavior during all of the loading steps. In particular, the WM models generally showed higher resistance than the JP model. This result indicates that the waveform micropile concept led to an increase in bearing capacity relative to the micropiles with a cylindrical shape.

The ultimate bearing capacity of each pile was estimated from the load-settlement curves. The FHWA manual defines the load corresponding to the slope of the load versus the micropile head settlement curve that exceeds $0.15 \mathrm{~mm} / \mathrm{kN}$ as the ultimate bearing capacity of the micropile. However, Jang and Han [14] found that the criterion of FHWA is not suitable to evaluate the ultimate bearing capacity for the waveform micropile because this configuration has a much larger diameter and requires a different construction method than the conventional micropile. Therefore, in this study, the load corresponding to a pile head settlement equal to $10 \%$ of the pile diameter (i.e., the $0.1 \mathrm{D}$ criterion) was considered the ultimate bearing capacity in reference to an earlier study conducted on the micropile [2]. The shaft diameter $\left(\mathrm{D}_{2}\right)$ of $300 \mathrm{~mm}$ of the WM models was used for the criterion with the assumption that the influence of the increase in diameter

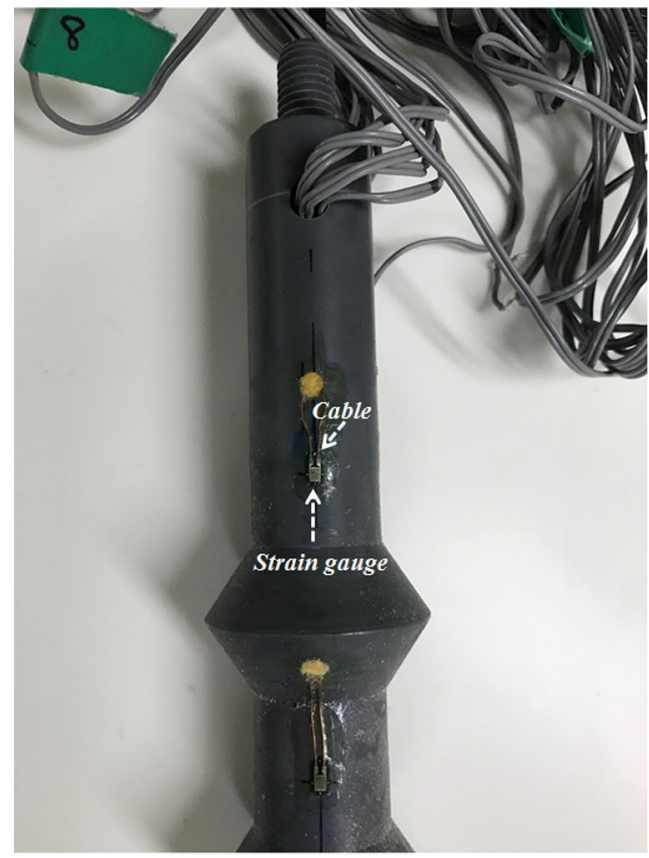

(a)

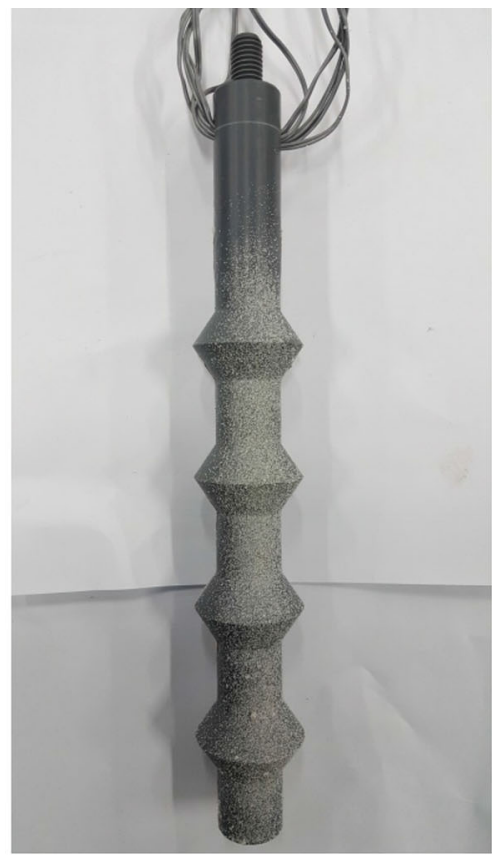

(b)

Fig. 6 Model pile preparation: a installing strain gauges and $\mathbf{b}$ surface roughening with sand particles 


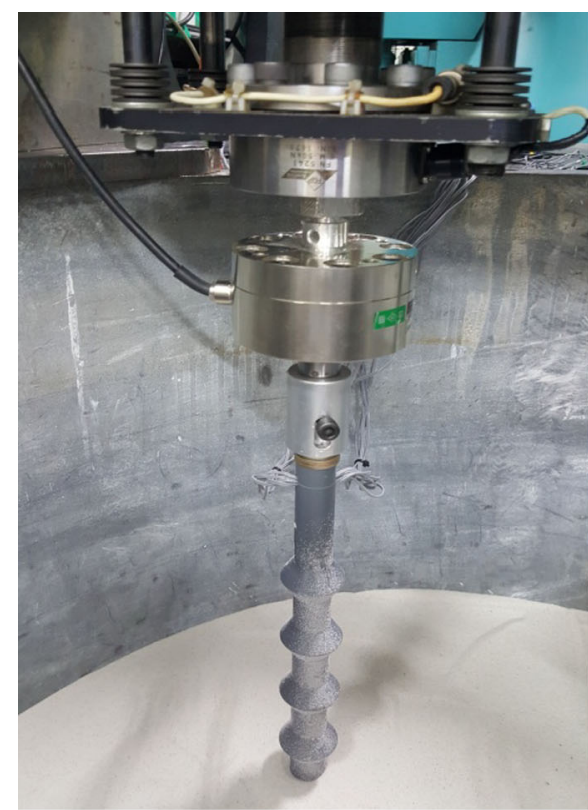

(a)

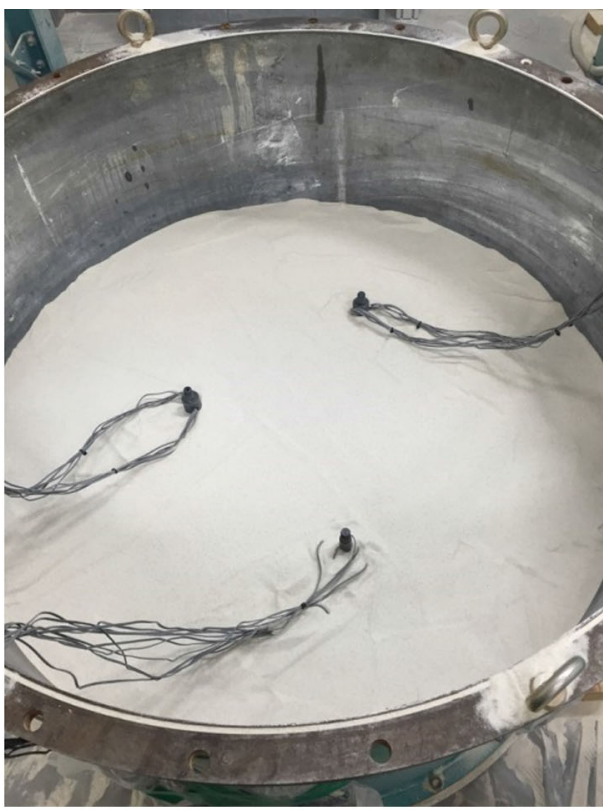

(b)

Fig. 7 Model pile installation steps: a 1st air-pluviation and tip installation and b 2nd air-pluviation

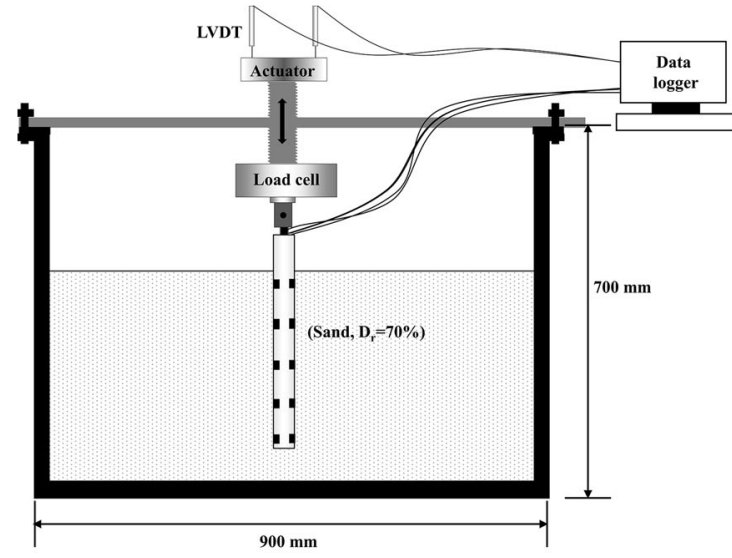

(a)

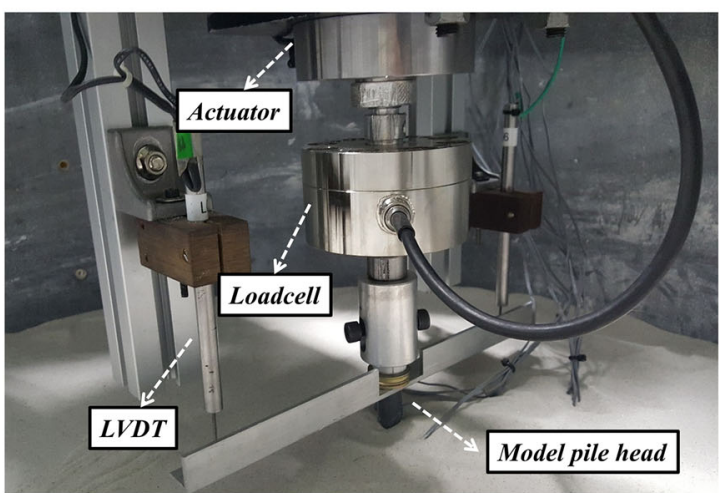

(b)

Fig. 8 Test setup: a schematic diagram and $\mathbf{b}$ instrumentation system

due to the shear key is not significant. Table 5 shows the ultimate bearing capacity obtained using the $0.1 \mathrm{D}$ criterion of $1040.0 \mathrm{kN}$ (MP), $1981.7 \mathrm{kN}$ (JP), $2079.8 \mathrm{kN}$ (WM-A), $2059.2 \mathrm{kN}$ (WM-B), $2208.8 \mathrm{kN}$ (WM-C), and $2167.1 \mathrm{kN}$ (WM-D). Relative to the MP model, the bearing capacity of the JP model and WM models increased by $47.5 \%$ and by an average of $51.1 \%$, respectively. The WM models showed a decrease in the settlement amount and an increase in the bearing capacity of up to $10.3 \%$ (WM-C) relative to that of the JP model. Among the WM models, the bearing capacities of the WM-C model with a single shear key at the bottom of the pile and those of the WM-D model with multiple shear keys along the pile depth were similar regardless of the pile shape. This finding is discussed in more detail using the analysis results of the axial load distribution.

\subsection{Axial load-transfer mechanism}

Based on the measured strains, the load-transfer curves in terms of the load corresponding to the initial displacement of the pile head of $5 \mathrm{~mm}$ to the ultimate state were obtained and are shown in Fig. 10. The distribution of the axial force along the pile shaft shows various shapes depending on the type of test model. Note that most of the resistance of the MP model shown in Fig. 10a was induced by the skin 


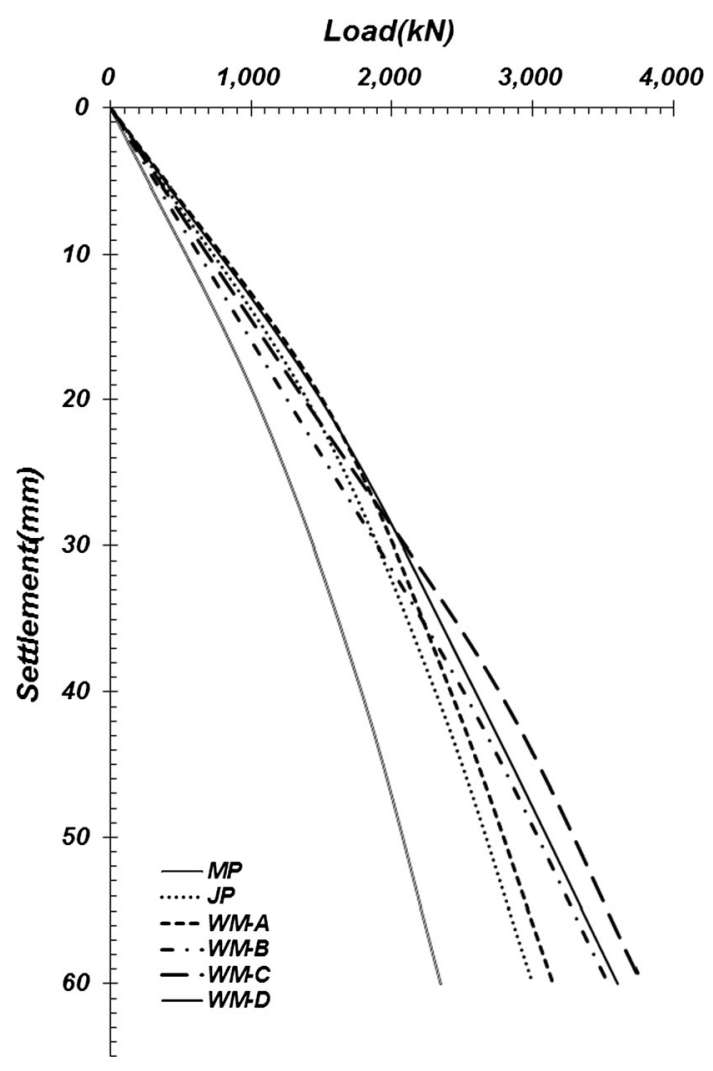

Fig. 9 Load-settlement curves for all test models (in protoscale)

Table 5 Ultimate bearing capacity estimated from the load-settlement curves

\begin{tabular}{lllllll}
\hline Description & MP & JP & $\begin{array}{l}\text { WM- } \\
\text { A }\end{array}$ & $\begin{array}{l}\text { WM- } \\
\text { B }\end{array}$ & $\begin{array}{l}\text { WM- } \\
\text { C }\end{array}$ & $\begin{array}{l}\text { WM- } \\
\text { D }\end{array}$ \\
\hline $\begin{array}{l}\text { Ultimate } \\
\text { bearing } \\
\text { capacity } \\
\left(\mathrm{kN} / \mathrm{m}^{2}\right)\end{array}$ & 1040.0 & 1981.7 & 2079.8 & 2059.2 & 2208.8 & 2167.1 \\
\hline
\end{tabular}

friction without considerable end bearing participation. In the JP model, in which the diameter increased to $300 \mathrm{~mm}$, the ratio of the load carried through the end bearing increased, as shown in Fig. 10b. The WM models, shown in Fig. 10c-f, were also supported by the resistance occurring from both the shaft and tip.

The shaft resistance of the waveform micropiles differed slightly according to the location of the shear keys shown in the graphs. For the WM-A model shown in Fig. 10c with an upper shear key, a similar behavior was observed as that of the JP model shown in Fig. 10b. This result indicates that the upper shear key had no effect on the increase in the shaft resistance. The shaft resistance of the WM-B model shown in Fig. 10d increased slightly over that of the JP model, but no significant difference was observed. In contrast, the WM-C model with a single shear key at the bottom section shown in Fig. 10e and the WM-D model with multiple shear keys shown in Fig. 10f presented a much higher bearing capacity than the other models. The bearing capacity of the two piles was similar regardless of the shape of the pile (i.e., the number of shear keys). In the load-transfer curves of the WM-C and WM-D models, the shaft resistance at the shear key from (1) to (3) of the WMD model was slightly higher than that of the WM-C model, but the difference was small. The high rate of increase in the shaft resistance mainly appeared in the shear key located at the bottom section in both models.

\subsection{Load-sharing characteristics for the waveform micropile}

In this section, a more detailed discussion of the loadsharing characteristics of the waveform micropiles is provided. Figure 11 shows the axial load-transfer curve corresponding to the ultimate bearing capacity for each pile. In the graph, the MP model presents the smallest bearing capacity, which was primarily developed by the shaft resistance. The JP model transferred more load to the tip than did the MP model and supported the loads together by the shaft and tip resistance. The load-sharing ratio for the WM models with the added shear key to the JP model varied depending on the pile shape, as mentioned previously. In particular, the shaft resistance of the WM-C and WM-D models increased over that the JP, WM-A, and WM-B models, and a relatively small load was transmitted to the tip.

Figure 12 shows the load-sharing ratio for the shaft and tip portions of each pile obtained from the load-transfer curve. In the figure, the micropile shows the typical characteristics of a friction pile with a high shaft resistance of $77 \%$ and relatively low tip resistance of $23 \%$. In the JP model, which has a $40 \%$ larger diameter than that of the MP model, the shaft resistance decreased to $54 \%$, while the tip resistance increased to $46 \%$. Moreover, a relatively high tip resistance of 39 and $49 \%$ was found in the WM-A model and WM-B model, respectively, both of which have a single shear key at the top and middle of the pile. Therefore, it was confirmed that the bearing capacity was not significantly altered in the WM-A and WM-B models due to the addition of the shear key.

Unlike other waveform micropiles with a single shear key, the load-sharing ratio of the shaft for the WM-C model increased to approximately $72 \%$, and only approximately $28 \%$ of the load was transferred to the pile tip. Relative to the JP model, which has the same shaft diameter as that of the WM-C model, the shear key at the bottom of the pile was found to provide additional shaft resistance. The load-bearing characteristics were closely 


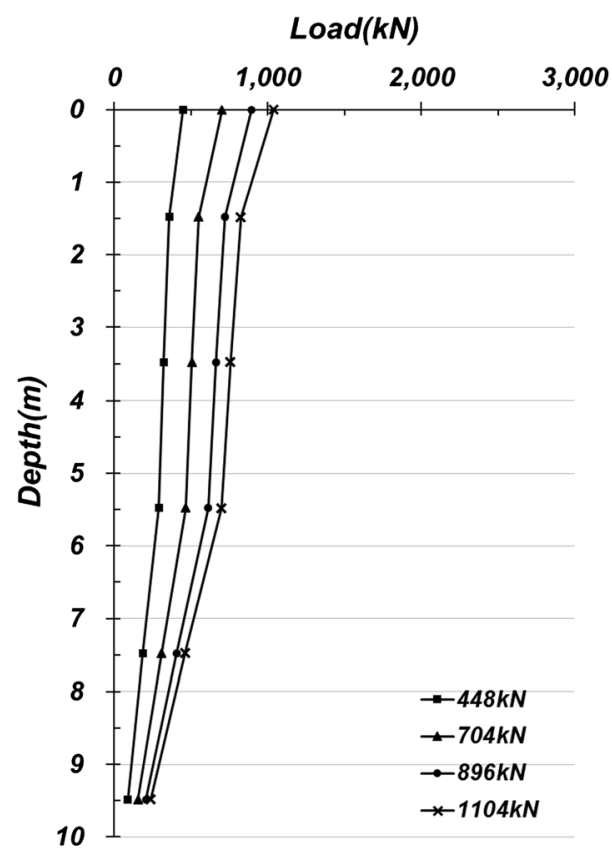

(a)

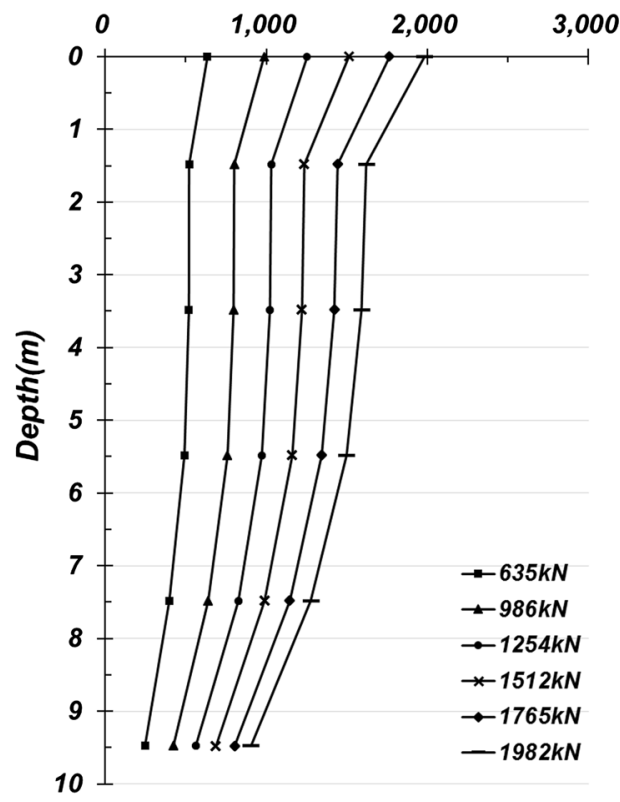

(b)

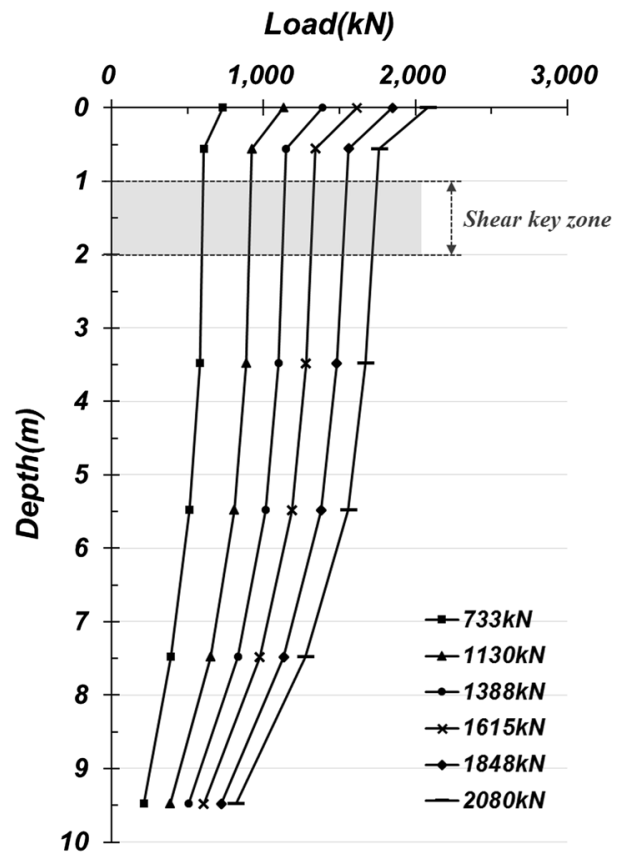

(c)

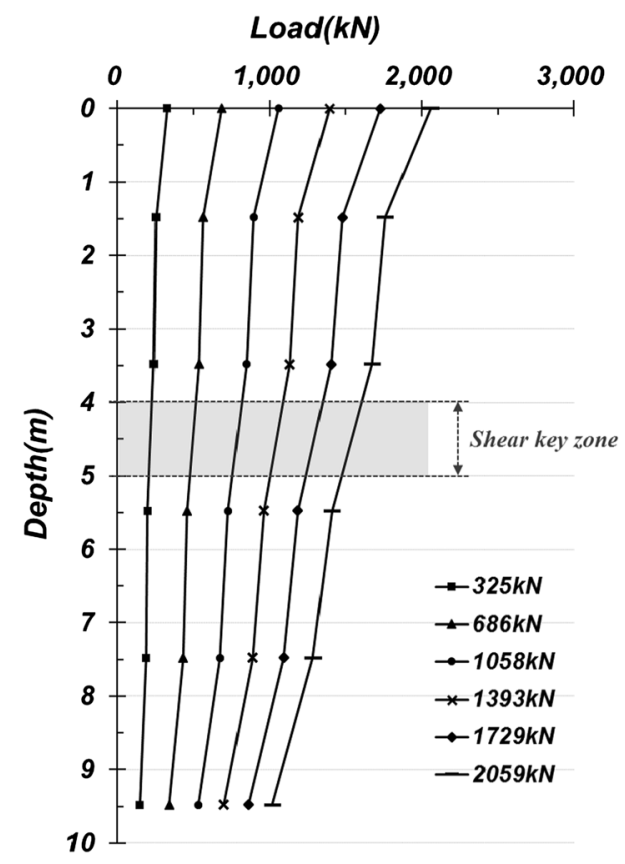

(d)

Fig. 10 Axial load-transfer curves: a MP and b JP, c WM-A, d WM-B, e WM-C, f WM-D

related to the pile shape determined by the arrangement of the shear key. However, the WM-D model with multiple shear keys along the pile length showed behavior similar to that of the WM-C model. This result indicates that the shaft resistance of the waveform micropile may not be increased proportionally with an increasing shear key number.

\subsection{Shear key effect on the axial behavior of waveform micropiles}

In the previous section, the analysis results of the loadsharing ratio for waveform micropiles indicated that the behavior of the pile is related to the location of the shear key. Therefore, the characteristics of the shaft resistance of 


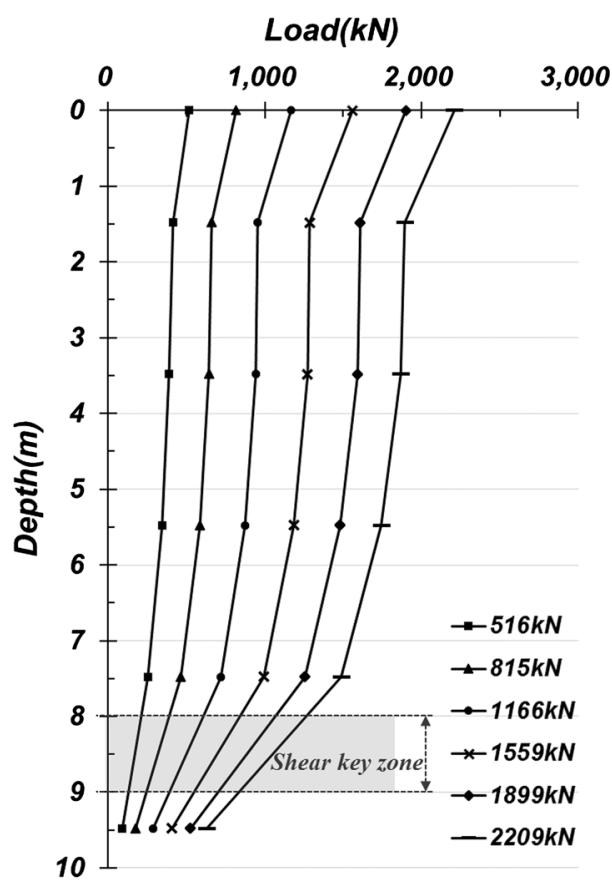

(e)

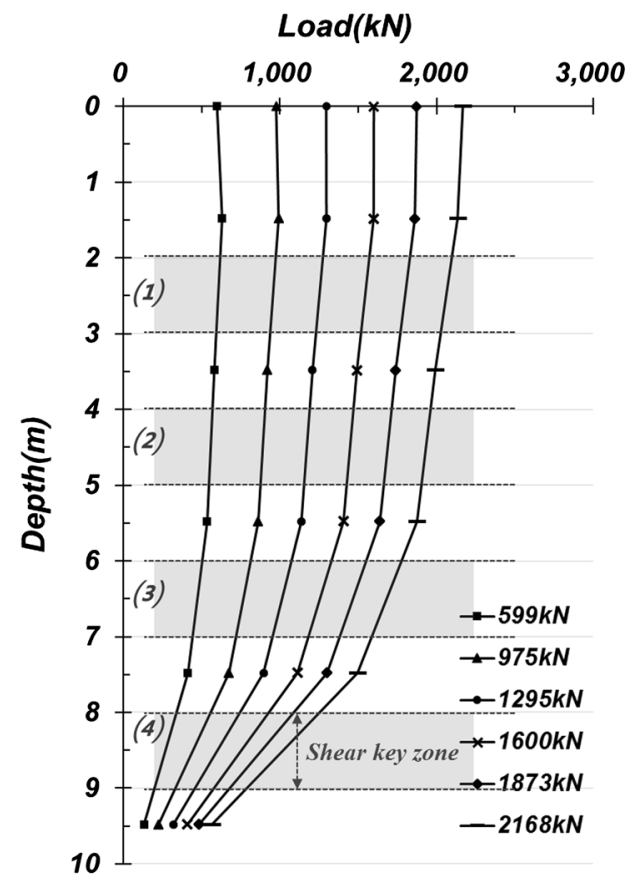

(f)

Fig. 10 continued
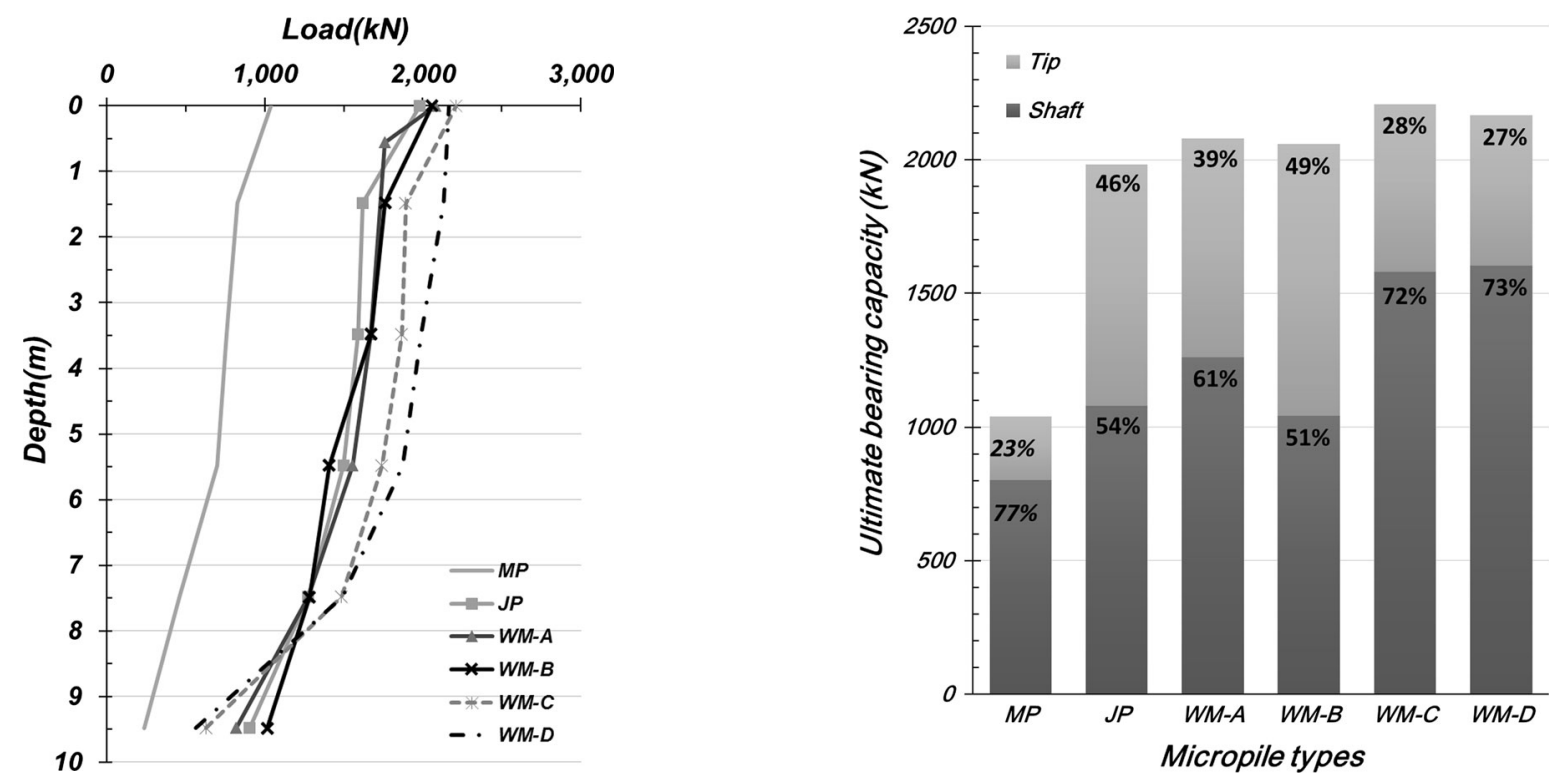

Fig. 11 Axial load distribution curves at ultimate bearing capacity of each model

each pile were investigated in detail through a comparison of the unit shaft resistance among the WM models. Figure 13 shows the unit shaft resistance of the WM models normalized to the JP model at the ultimate state. The shear key location is presented on the graph for each WM model to show the rate of increase in the shaft resistance near the shear key.

Fig. 12 Load-sharing ratio for the shaft resistance and tip resistance of each model

Figure 13a, b shows the WM-A and WM-B models, respectively, with the shear key at the top and middle of the model, showing that the shaft resistance increased near the shear key location and the increased area appeared to be relatively wide around the shear key. This behavior was observed because the upper part of the ground with the relatively low confining pressure led to an increase in the stress zone due to the shear key movement. However, 


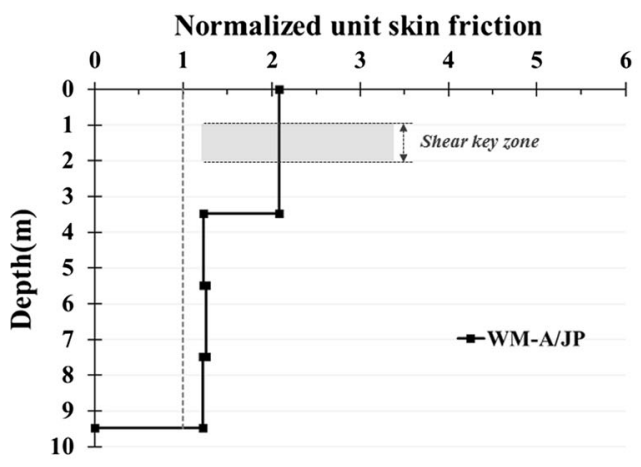

(a)

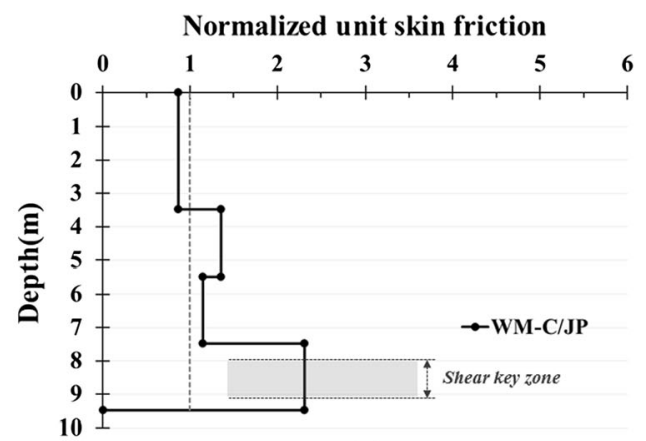

(c)

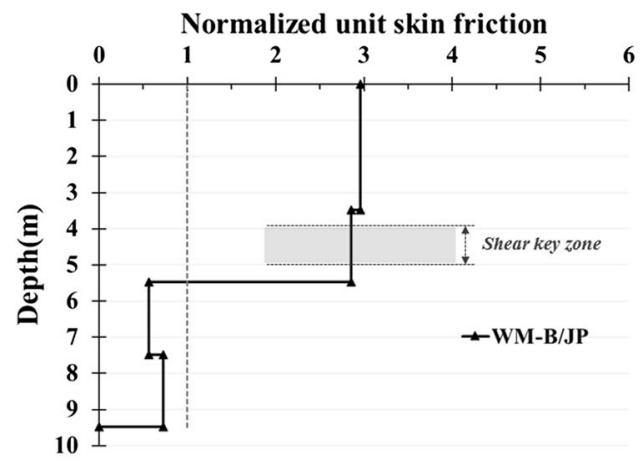

(b)

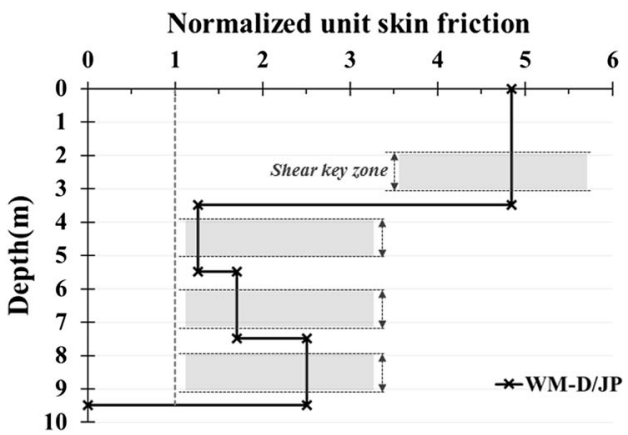

(d)

Fig. 13 Normalized shaft resistance: a WM-A and b WM-B, c WM-C, d WM-D

although the increased range of the shaft resistance widely expanded over the shear key location, the behavior of these two piles did not significantly improve from that of the JP model without the shear key, as shown in the load-sharing ratio graph (Fig. 12). This result indicates that the effect of the location of the shear key in the upper layer was insufficient to provide additional shaft resistance for the WM models.

The shaft resistance of the WM-C model in Fig. 13c, which showed noticeable improvement in the load-settlement relationship, also increased at the shear key location. However, the increase rate in the shaft resistance for the WM-C model was found to be similar to or smaller than that of the WM-A and WM-B models shown in Fig. 13a, b, respectively. Nonetheless, the shear key located at the bottom of the micropile, a region influenced by the high confining pressure, contributed to enhancing the shaft resistance. In Fig. 13d, the unit skin friction in the WM-D model, which showed substantially similar behavior to that of the WM-C model, increased near the top and bottom shear keys. Moreover, the resistance in the two shear keys located at the middle part of the micropile barely increased. This result implies that the number of shear keys is not the key factor affecting the increase in the bearing capacity of waveform micropile. The result also implies that better performance can be attained by the shear key when it is placed in the dense layer, which has larger confining pressure, when the waveform micropile is constructed in the actual field.

\subsection{Analysis of the axial bearing capacity of the waveform micropile}

In this section, the bearing capacity calculated from the formula of the FHWA manual is compared with the estimated value from the centrifuge test to examine the applicability of the existing design method for the waveform micropile. For the calculation of the bearing capacity in the prototype scale, the soil profile of the sand layer is determined based on the cone penetration test (CPT) test conducted on the dense silica sand [17]. Figure 14 shows the cone tip resistance $\left(\mathrm{q}_{\mathrm{c}}\right)$ profile for a depth of $10 \mathrm{~m}$ (250 $\mathrm{mm}$ at small scale). The characteristics of each layer are classified by referring to the relationship between $\mathrm{q}_{\mathrm{c}}$ and other soil properties, as shown in Table 6. It is assumed that the ground is composed of layers of loose sand $(0-2.7 \mathrm{~m})$, medium-dense sand $(2.7-7.3 \mathrm{~m})$, and dense sand $(7.3-10 \mathrm{~m})$.

The bearing capacity of all micropiles is predicted using Eq. 3, as suggested in the FHWA manual.

$Q_{a}=\frac{\alpha_{\text {bond }}}{\text { F.S. }} \cdot \pi \cdot D_{\text {bond }} \cdot L_{\mathrm{b}}$, 


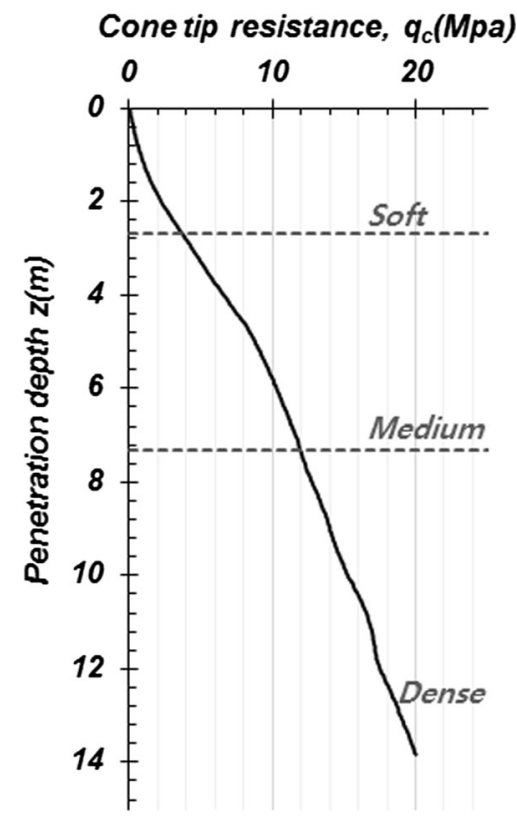

Fig. 14 Cone tip resistance $\left(q_{\mathrm{c}}\right)$ profile of silica sand $\left(D_{\mathrm{r}}=65 \%\right)$

Table 6 Relationship between $\mathrm{q}_{\mathrm{c}}$ and other soil properties [21]

\begin{tabular}{lllll}
\hline Consistency & $\begin{array}{l}\text { Relative } \\
\text { density }\left(D_{\mathrm{r}}\right)\end{array}$ & $N$ value & $\begin{array}{l}\text { Internal } \\
\text { friction }(\phi)\end{array}$ & $\begin{array}{l}\text { Cone } \\
\text { resistance }\left(q_{\mathrm{c}}\right. \\
\mathrm{MPa})\end{array}$ \\
\hline Very loose & $<0.2$ & $<4$ & $<30$ & $<2$ \\
Loose & $0.2-0.4$ & $4-10$ & $30-35$ & $2-4$ \\
Compact & $0.4-0.6$ & $10-30$ & $35-40$ & $4-12$ \\
Dense & $0.6-0.8$ & $30-50$ & $40-45$ & $12-20$ \\
Very dense & $>0.8$ & $>50$ & $>45$ & $>20$ \\
\hline
\end{tabular}

where $\alpha_{\text {bond }}$ is the grout-to-ground ultimate bond strength, $D_{\mathrm{b}}$ is the diameter of the drill hole, $L_{\mathrm{b}}$ is the bond length, and F.S. is the factor of safety. The $\alpha_{\text {bond }}$ values used in this study are shown in Table 7 . From the $\alpha_{\text {bond }}$ ranges for sand, the values for the type B micropile are applied to simulate the pressurized grouting effect applied to the model by attaching sand particles to the models.

When calculating the design bearing capacity of the waveform micropiles, the shaft diameter $\mathrm{D}_{2}$ is used, as it is assumed that the average pile diameter does not significantly increase with the addition of a shear key. As a result, the bearing capacity is $998.1 \mathrm{kN}$ for the MP model and $1663.5 \mathrm{kN}$ for the JP and WM models.

Table 8 shows the bearing capacities estimated from the proposed formula of the FHWA manual and the centrifuge test results. The calculation results of the test models are generally underestimated. In particular, the behavior of the JP model, which showed a relatively large tip resistance in terms of the load-sharing ratio, is not properly reflected in the calculation results. Moreover, the calculation results of
Table $7 \alpha_{\text {bond }}$ values for sand suggested by FHWA manual [10]

\begin{tabular}{lllll}
\hline Description & \multicolumn{2}{l}{$\begin{array}{l}\text { Grout-to-Ground Bond Ultimate } \\
\text { Strength, kPa }\end{array}$} \\
\cline { 2 - 5 } & $\begin{array}{l}\text { Type } \\
\text { A }\end{array}$ & Type B & Type C & Type D \\
& & & & \\
\hline $\begin{array}{c}\text { Sand (some silt) (fine, } \\
\text { loose-medium dense) }\end{array}$ & $70-145$ & $70-190$ & $95-190$ & $95-240$ \\
Sand (some silt, gravel) & $95-215$ & $120-360$ & $145-360$ & $145-385$
\end{tabular}

Type A: Gravity grout only

Type B: Pressure grouted through the casing during casing withdrawal

Type C: Primary grout placed under gravity head, then one phase of secondary "global" pressure grouting

Type D: Primary grout placed under gravity head, then one or more phases of secondary "global" pressure grouting

Table 8 Comparison of the bearing capacity from the FHWA formula and the centrifuge test

\begin{tabular}{|c|c|c|c|c|c|c|}
\hline $\begin{array}{l}\text { Evaluation } \\
\text { method }(\mathrm{kN})\end{array}$ & MP & JP & $\begin{array}{l}\text { WM- } \\
\text { A }\end{array}$ & $\begin{array}{l}\text { WM- } \\
\text { B }\end{array}$ & $\begin{array}{l}\text { WM- } \\
\text { C }\end{array}$ & $\begin{array}{l}\text { WM- } \\
\text { D }\end{array}$ \\
\hline $\begin{array}{l}\text { Calculation } \\
\text { result }\end{array}$ & 998.1 & 1663.5 & & & & \\
\hline $\begin{array}{l}\text { Centrifuge } \\
\text { test result }\end{array}$ & 1040.0 & 1981.7 & 2079.8 & 2059.2 & 2208.8 & 2167.1 \\
\hline $\begin{array}{l}\text { Increase rate } \\
\text { in bearing } \\
\text { capacity of } \\
\text { test piles } \\
(\%)\end{array}$ & 4.0 & 16.1 & 20.0 & 19.2 & 24.7 & 23.2 \\
\hline
\end{tabular}

the WM models differ significantly from the experimental results. These findings imply that the design equation of the FHWA manual is not suitable for waveform micropiles; thus, the development of an appropriate method to calculate the bearing capacity of the waveform micropile is required.

\section{Summary and conclusions}

In this study, a centrifugal model experiment was conducted to evaluate the axial behavior of the waveform micropile developed to improve the bearing capacity of the conventional micropile. The tests were conducted on six types of micropile models, namely the conventional micropile (MP), jet grouting micropile (JP), and waveform micropiles with various shapes (WM-A, WM-B, WM-C, and WM-D). From the test results, the load-settlement relationship and load-transfer mechanism were analyzed according to the shape of the waveform micropile.

As shown in the load-settlement curve, the overall bearing capacity of the jet grouting micropile and 
waveform micropile was superior to that of the conventional micropile. Moreover, the bearing capacity was increased in the WM models in which the shear key was added to the JP model. Among the WM models, the WM-C model with a single shear key at the pile bottom and the WM-D model with the multiple shear keys along the pile showed an increase in the bearing capacity by 10.3 and $8.6 \%$, respectively, relative to the JP model.

The axial load-transfer curve showed that the tip resistance values for the JP model and WM models were significantly increased when the shaft diameter increased by $40 \%$ more than in the MP model. In the load-sharing ratio by the shaft and tip portion of the piles, the result also showed that additional shaft resistance arose with the additional frictional force provided by the shear key of the waveform grout. However, in the WM-A and WM-B models, in which the shear key is located at the upper and middle part, respectively, the load-sharing ratio was similar to that of the JP model. In contrast, the shaft resistance of the WM-C and WM-D models was increased by $30 \%$ more than the JP model, and it was found that the applying the shear key to the bottom part of the pile, where dense soil exists with high confining pressure, can be effective for enhancing the bearing capacity. Regarding the bearing mechanism of the waveform micropile, further study is required to investigate the effects of the various soil types, soil strength, and loading conditions.

Considering that the purpose of the development of the waveform micropile was to improve the bearing capacity by increasing the shaft resistance of the conventional micropile, it was confirmed that the WM-C and WM-D models satisfied the purpose of this study. However, the current method for the calculation of the conventional micropile does not take into account the large load-sharing ratio caused by the tip resistance for the waveform micropile, resulting in underestimation of the bearing capacity. Therefore, it is necessary to consider the increased bearing capacity due to the shear key effect to predict the reasonable bearing capacity of the waveform micropile.

\begin{abstract}
Acknowledgements This research was supported by a grant from the project "Design and construction of artificial ground with the vertical spaces above existing urban infrastructure," which was funded by the Korean Institute of Civil Engineering and Building Technology (KICT) and "Developing and verifying the cost saving and highly efficient remodeling technologies of vertical extension for the aged multi-family housing" which is funded my the Korea Agency for Infrastructure Technology Advancement.
\end{abstract}

Open Access This article is distributed under the terms of the Creative Commons Attribution 4.0 International License (http://creative commons.org/licenses/by/4.0/), which permits unrestricted use, distribution, and reproduction in any medium, provided you give appropriate credit to the original author(s) and the source, provide a link to the Creative Commons license, and indicate if changes were made.

\section{References}

1. Abd Elaziz AY, El Naggar MH (2015) Performance of hollow bar micropiles under monotonic and cyclic lateral loads. J Geotech Geoenviron 140(5):04015010

2. Alnuaim AM, El Naggar H, El Naggar MH (2014) Performance of micropiled raft in sand subjected to vertical concentrated load: centrifuge modeling. Can Geotech J 52(1):33-45

3. Bolton MD, Gui MW, Garnier J, Corté JF, Bagge G, Laue J, Renzi R (1999) Centrifuge cone penetration tests in sand. Geotechnique 49(4):543-552

4. Bennett JK, Hothem NL (2010) Hollow bar micropiles for settlement control in soft clay. In: Proceedings of the 10th international workshop on micropiles, 22-25 September, Washington DC, USA

5. Choi C, Cho SD (2010) Field verification study for micropile load capacity. In: Proceedings of the 10th international workshop on micropiles, Washington DC, USA, 22-25 September

6. Drbe OFEH, El Naggar MH (2014) Axial monotonic and cyclic compression behaviour of hollow-bar micropiles. Can Geotech J 52(4):426-441

7. El Sharnouby MM, El Naggar MH (2012) Field investigation of axial monotonic and cyclic performance of reinforced helical pulldown micropiles. Can Geotech J 49(5):560-573

8. El Naggar MH, Sakr M (2000) Evaluation of axial performance of tapered piles from centrifuge tests. Can Geotech J 37(6): 1295-1308

9. Elsherbiny ZH, El Naggar MH (2013) Axial compressive capacity of helical piles from field tests and numerical study. Can Geotech J 50(12):1191-1203

10. Federal Highway Administration (FHWA) (2005) Micropile design and construction guidelines. US Department of Transportation, Washington, DC

11. Gómez JE, Rodriguez CJ, Mikitka J, Robinson HD (2008) Hollow core bar micropiles design parameters interpreted from 404 load tests. In: Proceedings of the 33rd annual conference on deep foundations, New York, USA, October 2008

12. Horikoshi $\mathrm{K}$, Matsumoto $\mathrm{T}$, Hashizume $\mathrm{Y}$, Watanabe $\mathrm{T}$, Fukuyama H (2003) Performance of piled raft foundations subjected to static horizontal loads. Int J Phys Model Geotech $3(2): 37-50$

13. Jang YE, Han JT (2014) Development on the micropile for applying to artificial ground above railroad site. Adv Sci Technol Lett 55:43-46

14. Jang YE, Han JT (2015) Study of load capacity of waveform micropile by centrifuge test. In: Proceedings of the 25th international offshore and polar engineering conference, Hawaii, USA, pp 21-26

15. Jang YE, Han JT (2017) Field study on the axial bearing capacity and load transfer characteristic of waveform micropile. Can Geotech J. https://doi.org/10.1139/cgj-2017-0155

16. Kim DS, Kim NR, Choo YW, Cho GC (2013) A newly developed state-of-the-art geotechnical centrifuge in Korea. KSCE J Civ Eng 17(1):77-84

17. Kim JH, Choo YW, Kim DJ, Kim DS (2015) Miniature cone tip resistance on sand in a centrifuge. ASCE Geotech Geoenviron J 142(3):04015090

18. Kim SH, Choi J, Lee JM, Lee J, Jung CY (2016) Improved load carrying behavior of perfobond rib-installed partially expanded micropiles. Geotech Test J 39(4):633-647

19. Ko HY (1988) Summary of the state-of-the-art in centrifuge model testing. In: Centrifuge in soil mechanics, pp 11-28

20. Kyung D, Kim D, Kim G, Lee J (2017) Vertical load-carrying behavior and design models for micropiles considering foundation configuration conditions. Can Geotech J 54(2):234-247 
21. Mayerhof GG (1956) Penetration test and bearing capacity of cohesionless soils. In: Proceedings of the ASCE, J Soil Mech Found Div 82(1):866

22. Papadopoulou K, Saroglou H, Papadopoulos V (2014) Finite element analyses and experimental investigation of helical micropiles. Geotech Geol Eng 32(4):949-963

23. Spagnoli G, Gavin K, Brangan C, Bauer S (2015) In situ and laboratory tests in dense sand investigating the helix-to-shaft ratio of helical piles as a novel offshore foundation system. Front Offshore Geotech 3:643-648

24. Timothy MJ, Bean JJ (2012) MiniJET: a new type of micropile. Grouting and deep mixing. American Society of Civil Engineers (ASCE), New Orleans, pp 1095-1104

25. Toyosawa Y, Itoh K, Kikkawa N, Yang JJ, Liu F (2013) Influence of model footing diameter and embedded depth on particle size effect in centrifugal bearing capacity tests. Soils Found 53(2):349-356

26. Tsukada K, Miura Y, Tsubokawa Y, Otani GL (2006) Mechanism of bearing capacity of spread footings reinforced with micropiles. Soils Found 46(3):367-376

27. Vickars RA, Clemence SP (2000) Performance of helical piles with grouted shafts. In: New technological and design developments in deep foundations, Proceedings of Sessions of GeoDenver 2000. American Society of Civil Engineers, Reston, VA

\section{Publisher's Note}

Springer Nature remains neutral with regard to jurisdictional claims in published maps and institutional affiliations. 